\title{
PEMBELAJARAN KARAWITAN PADA KEGIATAN EKSTRAKURIKULER
}

\author{
Satrio Wahyu Sanyoto ${ }^{1}$, Ninik Harini ${ }^{2}$, dan Rully Aprilia Zandra ${ }^{3}$ \\ Program Studi Pendidikan Seni Tari dan Musik Jurusan Seni dan Desain Fakultas Sastra \\ Universitas Negeri Malang \\ E-mail: satrioshete@gmail.com¹,ninikharini.fs@um.ac.id², rullyzandra.fs@um.ac.id ${ }^{3}$
}

\begin{abstract}
Abstrak
Tujuan penelitian ini dilakukan untuk mendeskripsikan (1) Perencanaan pembelajaran (2) Pelaksanaan pembelajaran (3) Evaluasi pembelajaran. Metode penelitian yang digunakan adalah deskriptif kualitatif. Narasumber dari penelitian ini adalah Guru ekstrakurikuler, Pembina ekstrakurikuler, dan Kepala sekolah. Teknik pengumpulan data menggunakan observasi, wawancara, dan dokumentasi. Kegiatan analisis data dimulai dari tahap reduksi data, kemudian penyajian data, dan mengambil kesimpulan digunakan saat pengecekan keabsahan data triangulasi teknik dan sumber. Hasil penelitian ini menunjukkan bahwa: (1) Perencanaan pembelajaran tidak membuat RPP, namun RPP cuma ada dipikran guru dan guru hanya menyiapkan notasi yang sudah di print. (a) tujuan pembelajaran ekstrakurikuler karawitan adalah tampil diacara pendopo kabupaten dan menang lomba di tingkat kabupaten maupun provinsi (b) materi tentang teori dasar karawitan, cara memainkan, pola irama, pola notasi, cara mengaransemen dan materi utama yaitu Gending Lesung Jumengglung (c) metode yang digunakan adalah metode ceramah, metode demonstrasi dan metode drill, (d) media yang digunakan satu set gamelan laras pelog slendro. LCD Proyektor, microphone, Soundsystem, alat tulis dan papan tulis yang disediakan oleh sekolah. (2) Pelaksanaan pembelajaran ekstrakurikuler di SMAN 1 Karangan guru merendah kepada peserta didik dan guru selalu santai dari bahasanya, motivasinya, sikapnya, dan hukumannya yang ringan. (3) Evaluasi pembelajaran di SMAN 1 Karangan guru melakukan pemilihan bagi peserta didik yang rajin untuk mengikuti lomba, sedangkan peserta didik yang kurang rajin akan di pentaskan di sekolahan.
\end{abstract}

Kata Kunci: Proses Pembelajaran, Karawitan, Ekstrakurikuler, SMAN 1 Karangan, Trenggalek.

\section{THE LEARNING OF KARAWITAN IN EXTRACURRICULAR ACTIVITIES}

\begin{abstract}
The purpose of this study was to describe (1) Learning planning (2) Implementation of learning (3) Evaluation of learning.The research method used is descriptive qualitative. Resource persons from this study were extracurricular teachers, extracurricular coaches, and school principals. The technique of collecting data uses observation, interviews, and documentation. The data analysis activity starts from the data reduction stage, then presents the data, and draws conclusions used when checking the validity of triangulation techniques and source data. The results of this study indicate that: (1) Planning for musical extracurricular learning is not made in writing but is guided by work programs and training schedules, including: (a) musical extracurricular learning goals are as developing talents in the music field and as learning material for appropriate knowledge with the conditions of the students (b) the material about the basic theory of music, how to play, the pattern of rhythm, the pattern of notation, how to arrange and the main material namely Gending Lesung Jumengglung (c) the method used is the lecture method, demonstration method andmethod drill, (d) the media used is a set of gamelan pelog slendro. LCD Projector, microphone,
\end{abstract}


sound system, stationery and the blackboard provided by the school. (2) Extracurricular learning at SMAN 1 Karangan, (a) initial activities, (b) core activities, (c) final activities. (3) Evaluation of learning in Senior High School 1 Karangan is divided into two, namely (a) process evaluation, (b) outcome assessment.

Keywords: Learning Process, Karawitan, Extracurricular, SMAN 1 Karangan, Trenggalek.

\section{PENDAHULUAN}

Pendidikan seni adalah usaha sadar untuk mewariskan atau menularkan kemampuan berkesenian sebagai perwujudan transformasi kebudayaan dari generasi ke generasi yang dilakukan oleh para seniman atau pelaku seni kepada siapapun yang terpanggil (Jamalus,88) (Rahmawati, Pratamawati, and Zandra 2017), bahwa "pendidikan seni adalah upaya untuk mewariskankemampuanberkesenianyangdapat dilakukan oleh seniman" pelaku seni, pendidik seni, atau siapapun yang memiliki kemampuan berkesenian dan mampu membelajarkan. Hal tersebut ditambahkan oleh Jazuli (2008 : 14), bahwa pendidikan seni digunakan untuk menyiapkan siswa melalui kegiatan kegiatan pembimbingan, pembelajaran, dan pelatihan agar siswa memiliki kemampuan untuk berkesenian.

Pembelajaran merupakan suatu proses interaksi yang dilakukan antara peserta didik dan guru dimana akan diakhiri dengan evaluasi hasil belajar (Dimyanti dan Mudjiono, 2006:3). Pembelajaran adalah kunci utama demi tercapainya tujuan yang telah ditentukan.

Ekstrakurikuler dilaksanakan oleh peserta didik diluar jam pembelajaran intrakulikuler dan kegiatan kokulikuler, dibawah bimbingan dan pengawasan satuan pendidikan, bertujuan untuk mengembangkan potensi bakat, minat, kemampuan, kepribadian, kerjasama, dan kemandirian peserta didik. Kegiatan ini dilakukan berkala atau hanya dalam waktuwaktu tertentu dan ikut dinilai (Permendikbud, 2014:62).

Proses pembelajaran seni karawitan pada kegiatan ekstrakulikuler di SMAN 1 Karangan. Kegiatan tersebut dilakukan setiap hari sabtu jam 15.00 WIB (wawancara dengan Esti selaku pembina ekstrakurikuler pada tanggal 25 Februari 2018). Seni Karawitan di SMAN 1 Karangan juga tergabung dalam grup PPST (Paguyuban Pencinta Seni Tradisi) Jawa Timur (wawancara dengan Esti selaku pembina ekstrakurikuler pada tanggal 25 Februari 2018).Ekstrakurikuler karawitan di SMAN 1 Karangan selalu mengembangkan teknik-teknik garapan baru dan menggunakan gaya Jawa Timuran dan gaya Jawa Tengahan (wawancara dengan Dedi selaku guru ekstrakurikuler pada tanggal 31 Maret 2018). Ekstrakurikuler di SMAN 1 Karangan diikuti oleh peserta didik yang mempunyai bakat dan minat dalam bidang karawitan dari kelas 10 sampai kelas 11. Pengelolaan ekstrakurikuler SMAN 1 Karangan cukup baik. Fasilitasnya cukup memadai terdapat satu set gamelan laras pelog dan laras slendro. (wawancara Dedi selaku guru ekstrakulikuler pada tanggal 31 Maret 2018). Para peserta didik yang tergabung di ekstrakurikuler karawitan ini merupakan peserta didik yang sudah bisa dibidang karawitan. Selain itu, juga belum diketahui strategi guru untuk melatih peserta didik yang sudah bisa agar selalu mendapatkan prestasi disetiap perlombaan yang di ikuti. Guru ekstrakurikuler ini dalam pembelajarannya mempunyai beberapa tahapan yaitu tentang perencanaan

Sejak awal berdirinya ekstrakurikuler karawitan ini selalu mendapatkan beberapa prestasi. Ekstrakurikuler karawitan ini dalam perjalanannya, dari tahun 2013 hingga 2019 memiliki beberapa prestasi antara lain : penata iringan terbaik Festival Jaranan Trenggalek Terbuka(FJTT) pada tahun 2013, penata iringan terbaik Festival Jaranan Trenggalek Terbuka (FJTT) pada tahun 2014, penata iringan terbaik kethoprak di Jatim Fair tahun 2015, penata iringan Festival Jaranan Trenggalek Terbuka 
tingkat pelajar se-kabupaten pada tahun 2016, juara 1 lomba musik patrol se-karisidenan Kediri pada tahun 2017, juara 1 lomba musik patrol tradisi tingkat kabupaten pada tahun 2018, juara 1 PCSP ( Pekan Cipta Seni Pelajar) tingkat kabupaten pada tahun 2019.

Keberhasilan pembelajaran ekstrakurikuler ini menjadikan ekstrakurikuler karawitan di SMAN 1 Karangan terkenal dikalangan masyarakat. Hal tersebut dibuktikan adanya undangan kelompok karawitan ini dalam berbagai event di kabupaten Trenggalek. Berdasarkan hal tersebut, menarik untuk dikaji bagaimana proses pembelajaran karawitan pada kegiatanekstrakurikuler di SMAN 1 Karangan. Semua hal tersebut dituliskan dalam penelitian ini yang berjudul "Proses Pembelajaran Karawitan pada Kegiatan Ekstrakurikuler di SMAN 1 Karangan.

\section{Teori}

Proses pembelajaran adalah suatu interaksi yang melibatkan antara peserta didik dengan guru yang dilakukan melalui tahapan-tahapan pembelajaran. Menurut Abdul Majid (2015:5) bahwa "proses pembelajaran adalah suatu konsep dari dua dimensi kegiatan (belajar dan mengajar) yang harus direncanakan dan diaktualisasikan, serta diarahkan pada pencapaian tujuan atau penguasaan sejumlah kompetensi dan indikatornya sebagai gambaran hasil belajar" Dalam proses pembelajaran terdapat beberapa tahapan yaitu perencanaan, pelaksanaan, dan evaluasi (Amri 2010:56).

Proses pembelajaran itu sendiri harus melibatkan guru dan peserta didik bertujuan untuk mencapai tujuan pendidikan. Proses pembelajaran ini juga terdapat tahap-tahapan diantar lain : perencanaan, pelaksanaan, dan evaluasi.

Perencanaan dibentuk oleh guru sebelum melakukanprosesbelajarmengajar.Perencanaan adalah menyusun serangkaian kegiatan dalam proses pembelajaran yang akan dilakukan untuk mencapai tujuan yang berharga. Menurut Abdul Majid (2013:15) menjelaskan bahwa "Perencanaan pembelajaran adalah menyusun langkah-langkah yang akan dilakukan untuk mencapai tujuan yang telah ditentukan".
Perencanaan adalah langkah awal untuk disusun oleh guru sebelum kegiatan pembelajaran dilaksanakan. Perencanaan disusun selaku pedoman untuk mencapai tujuan yang telah ditentukan.

Tujuan pembelajaran yang dilakukan oleh guru dan siswa dalam proses pembelajaran yang diharapkan dari siswa sebagai hasil belajar. Menurut H. Daryanto (2012:58), bahwa tujuan pembelajaran adalah tujuan yang menggambarkan tentang pengetahuan, kemampuan, ketrampilan dan sikap yang harus dimiliki siswa akibat dari hasil pembelajaran yang dinyatakan dengan cara membentuk tingkah laku yang dapat diamati dan diukur. Dengan demikian, tujuan pembelajaran adalah supaya siswa mampu mengalami perubahan tingkah laku tertentu yang sesuai dengan tingkatan taksonomi yang sudah dirumuskan terlebih dahulu. Adapun taksonomi terdapat tiga komponen yaitu kognitif, afektif, dan psikomotorik.

Tujuan pembelajaran adalah proses belajar yang diharapkan terjadi, dimiliki atau bisa dikuasai oleh peserta didik setelah mengikuti proses kegiatan pembelajaran tersebut.

Pada pelaksanaan pembelajaran guru selalu memberikan materi pembelajaran.

Materi pembelajaran merupakan bahan substansi pembelajaran untuk membantu guru dalam kegiatan belajar mengajar. Menurut Djamarah dan Zain (2014:43) menjelaskan bahwa materi pembelajaran adalah substansi yang akan disampaikan dalam proses belajar mengajar. Tanpa adanya materi, proses pembelajaran tidak dapat berlangsung. Guru haruslah bisa menguasai materi yang akan diajarkan kepada siswa.

Materi Pembelajaran suatu perangkat untuk membantu guru dalam melakukan kegiatan belajar mengajar untuk memenuhi standar kompetensi yang ditetapkan.

Pada pembelajaran harus ada metode karenametode pembelajaran merupakan teknik penyajian yang sudah harus dikuasai oleh guru untuk mengajar. Menurut Sanjaya $(2011,147)$, bahwa metode adalah cara yang dilakukan untuk mengimplementasikan rencana yang 
sudah disusun dalam suatu kegitan nyata agar tujuan yang telah disusun dapat tercapai secara optimal.

Di bawah ini akan menjelaskan beberapa metode pembelajaran yang digunakan. Metode yang digunakan dalam pembelajaran menurut Sanjaya Wina (2011:147) diantara lain yaitu :

Metodeceramahadalahcaramenyampaikan materi kepada peserta didik dengan secara lisan. Menurut Abdul Majid (2013:137) bahwa "Yang perlu diperhatikan, hendaknya ceramah mudah diterima, isinya mudah dipahami serta mampu menstimulasi pendengar (anak didik) untuk melakukan hal-hal yang baik dan benar dari isi ceramah yang disampaikan".

Metode demonstrasi adalah serangkaian strategi yang digunakan oleh guru untuk mengembangkan dengan cara memberikan pengalaman belajar melalui perbuatan melihat dan mendengarkan. Menurut Sanjaya (2011:152), bahwa metode demonstrasi adalah bentuk metode penyajian pelajaran dengan memperagakan dan mempertunjukkan kepada siswa tentang suatu proses, situasi, atau benda tertentu, baik sebenarnya atau hanya cuma tiruan. Dalam proses pembelajaran, demonstrasi dapat digunakan untuk mendukung sebuah keberhasilan pembelajaran ekspositori dan inkiuri.

Metode demonstrasi adalah metode untuk mengajar yang menggunakan peragaan untuk memperlihatkan dan memperjelas suatu pengertian kepada peserta didik.

Metode drill merupakan cara mengajar guru dengan memberikan latihan-latihan terhadap apa yang telah dipelajari siswa sehingga memperoleh suatu ketrampilan tertentu. Menurut Nana Sudjana (1995:86), bahwa metode drill merupakan suatu kegiatan untuk meningkatkan ketrampilan siswa. Metode drill adalah metode dalam pengajaran guna untuk melatih siswa terhadap bahan yang sudah diajarkan/diberikan agar mempunyai ketangkasan atau ketrampilan dari apa yang telah dipelajari (Zandra 2019).

Metode drill adalah suatu cara mengajar guru untuk memberikan latihan-latihan terhadap apa yang telah dipelajari siswa sehingga memperoleh suatu ketrampilan tertentu (Zandra 2014).

Pada pembelajaran berlangsung guru menyiapkan media pembelajaran guna untuk mempermudah siswa memamahami materi.

Media pembelajaran adalah suatu alat yang digunakan guru untuk membantu proses pembelajaran. Dalam proses pembelajaran guru menggunakan media komunikasi bertujuan dapatmempermudahdanmengefektifkan proses pembelajaran yang lebih menarik. Dalam hal ini dijelaskan oleh Sanjaya (2011:162), bahwa suatu proses komunikasi selalu melibatkan tiga komponen, yaitu komponen mengirim pesan (guru), komponen menerima pesan (siswa), dan komponen pesan itu sendiri yang biasanya berupa materi pelajaran.

Media pembelajaran adalah sekumpulan berbagai jenis komponen untuk membantu guru yang ada didalam lingkungan peserta didik.

Pelaksanaan pembelajaran adalah suatu proses kegiatan belajar mengajar yang akan dilaksanakan mulai dari kegiatan awal, kegiatan inti, dan kegiatan penutup untuk mencapai tujuan tertentu. Menurut Nana Sudjana (2010:136) bahwa "pelaksanaan pembelajaran adalah suatu proses yang diatur sedemikian rupa menurut langkah-langkah tertentu agar pelaksanaan mencapai hasil yang diharapkan"yang akan dilaksanakan untuk mencapai tujuan tertentu yang telah dirumuskan sebelum pembelajaran dimulai. Dalam pelaksanaan pembelajaran,pendidik melakukan beberapa tahap pelaksanaan pembelajaran antara lain kegiatan awal, kegiatan inti, dan akhir.

Setelah melaksanakan pembelajaran guru melakukan evaluasi pembelajaran bertujuan untuk mengetahui hasil belajar peserta didik dalam menerima materi yang diajarkan oleh guru.Hal tersebut dikemukakan oleh Abdul Majid (2012 : 224), bahwa "evaluasi terhadap hasil belajar bertujuan untuk mengetahui ketuntasan siswa dalam menguasai kompetensi dasar". Setelah guru mengevaluasi hasil belajar, guru dapat memperoleh manfaat untuk melakukan perbaikan yang tepat kepada peserta didik(Khusairi, Zandra, and Harini 2019). 
Dalam evaluasi pembelajaran ada penilaian proses dan penilaian hasil.

Penilaian proses dilakukan pada pengamatan sikap peserta didik pada saat berlangsungnya proses pembelajaran. Dengan Demikian merupakan bentuk penilaian nontes. Dalam penilaian proses memuat 5 aspek antara lain: a) keunggulan, b) kedisiplinan, c) keaktifan, d) keberanian, e) kerjasama, f) inisiatif.

Penilaian hasil belajar adalah untuk mengukur kemampuan antar peserta didik yang satu beserta peserta didik yang lainnya, untuk mengukur keberhasilan proses pendidikan dan peengajaran yang dilaksanakan guru dalam kelas yang mencakup beberapa aspek seperti, aspek intelektual, sosial emosional, moral dan ketrampilan.

\section{METODE}

Jenis penelitian ini adalah kualitatif dan menggunakan pendekatan deskritif dan kualitatif. Penelitian ini mengkaji tentang Proses pembelajaran karawitan pada kegian ekstrakurikuler di SMAN 1 Karangan Trenggalek yang berfokus pada proses pembelajaran karawitan pada kegiatan ekstrakurikuler.

Peran peneliti adalah sebagai instrumen utama untuk memperoleh informasi, karena yang mengetahui latar belakang dalam penelitian ini adalah peneliti, oleh karena itu tidak bisa diwakilkan oleh orang lain. Lokasi penelitian dilakukan diSMAN 1 Karangan yang beralamat di Jl. Raya Trenggalek-Ponorogo Km 3 Ds. Buluagung Kec. Karangan Kab. Trenggalek. Narasumber dalam penelitian ini adalah adalah Guru ekstrakurikuler, pembina ekstrakurikuler, dan Kepala sekolah.

Teknik pengumpulan data dilakukan dengan tiga cara, yaitu observasi, wawancara dan dokumentasi. Analisis data dilakukan dengan tiga tahap, yaitu reduksi data, penyajian data dan penarikan kesimpulan. Pengecekan keabsahan temuan dilakukan dengan

cara triangulasi data. Triangulasi data adalah teknik pemeriksaan keabsahan temuan. Pengecekan keabsahan temuan dilakukan menggunakan triangulasi teknik dan triangulasi sumber, peneliti mencari data dari berbagai sumber dan melakukan penelitian dengan menggunakan sumber data dari observasi, wawancara dan dokumentasi. Langkah pertama yang dilakukan oleh peneliti adalah mengumpulkan data tentang perencanaan pembelajaran, pelaksanaan pembelajaran, dan evaluasi pembelajaran dengan cara observasi , dokumentasi, wawancara dengan Dedy (selaku guru ekstrakurikuler karawitan), dan Esti (selaku Pembina ekstrakurikuler karawitan). Langkah selanjutnya peneliti mereduksi data tentangperencanaanpembelajaran, pelaksanaan pembelajaran, dan evaluasi pembelajaran supaya data yang akan disajikan valid. Setelah mereduksi data peneliti melakukan penyajian data tentang perencanaan pembelajaran, pelaksanaan pembelajaran, evaluasi pembelajaran dengan cara mengumpulkan data dari observasi, dokumentasi, dan wawancara. Setelah mengumpulkan data, mereduksi data, penyajian data peneliti menarik kesimpulan data yang diperoleh melalui observasi, dokumentasi, dan wawancara.

Pengumpulandatakembalidilakukankarena peneliti belum cukup banyak mendapatkan data tentang evaluasi pembelajaran dengan cara wawancara dengan Reny (selaku kepala sekolah), Dedy (selaku guru ekstrakurikuler karawitan), dan Esti (selaku pembina ekstrakurikuler karawitan). Peneliti tidak mereduksi data karena data yang diperoleh cukup rinci dan tidak ada data yang dibuang. Langkah selanjutnya peneliti melakukan penyajian data tentang evaluasi pembelajaran melalui wawancara yang diperoleh dari Reny (selaku kepala sekolah), Dedy (selaku guru ekstrakurikuler karawitan), Esti (selaku Pembina ekstrakurikuler karawitan). Langkah terakhir yang dilakukan peneliti yaitu penarikan kesimpulan.

\section{HASIL DAN PEMBAHASAN}

Perencanaan pembelajaran yang dilakukan guru ekstrakurikuler karawitan di SMAN 1 Karangan tidak membuat tentang Rancangan Rencana Pembelajaran atau RPP secara tertulis, 
namun RPP/SAP cuma ada dipikiran guru. Guru menyiapkan notasi yang sudah di print. Selain itu, guru juga menyiapkan program kerja dan membuat jadwal latihan yang sesuai dengan kemampuan peserta didik.

Pihak sekolah juga tidak meminta untuk mempersiapkan adanya RPP secara tertulis pada kegiatan ekstrakurikuler tersebut, tetapi secara umum pihak sekolah hanya meminta materi yang sesuai dengan kemampuan peserta didik, lalu selanjutnyamenggarap pola gending kembali untuk persiapan berbagai lomba ataupun acara yang dilakukan oleh sekolah maupun oleh kabupaten.

Adapun secara konsep guru ekstrakurikuler karawitan SMAN 1Karangan Trenggalek, menerapkan perencanaan pembelajaran yang meliputi:(a)tujuanpembelajaranekstrakurikuler karawitan adalah tampil di pendopo kabupaten dan menang lomba ditingkat kabupaten maupun provinsi. Ekstrakurikuler ini selalu tampil di pendopodengan lagu yang ditargetkan antara lain : Mangga tindak Trenggalek, Pantai Prigi yang Indah, Lesung Jumengglung, tembang dolanan. Ekstrakurikuler ini juga menang lomba PSCP (Pekan Cipta Seni Pelajar) tingkat

kabupaten), sebelumnya guru sudah mengetahui selera juri yang dibidik antara lain : teknik mengacu kekompakan, dan kreativitas kekayaan garap, karawitan dengan gaya Jawa Timuran, sedangkan lagu yang dibawakan harus mencerminkan pada tema, dan aliran musik tradisi kreasi tidak boleh dicampur dengan alat musik elektrik (b) materi yang diberikan yaitu gendinggending Lesung Jumengglung. Gending Lesung Jumengglung ini sangat sederhana, namun dalam bimbingan dan arahan dari guru serta keterlibatan peserta didik menjadikan gending ini memiliki nuansa baru dari aslinya, karena gending tersebut dibuat dengan beberapa pola irama dan adanya penambahan instrumen,(c) metode yang digunakan adalah metode ceramah, metode demonstrasi dan metode drill, (d) media yang digunakan adalah satu set gamelan laras pelogslendro, LCD Proyektor, Microphone, Soundsystem, dan papan tulis yang disediakan oleh sekolah.
Berdasarkan hasil pengamatan, padaproses pelaksanaan pembelajaran guru merendah kepada peserta didik dengan tujuan peserta didik bisa nyaman, patuh perintah guru dan tidak takut dengan gurunya, agar pembelajaran menjadi lancar tetapi juga ada kekurangannya yaitu peserta didik yang menganggap dirinya sudah bisa selalu meremehkan gurunya. Guru selalu santai dengan peserta didik seperti teman sendiri dari bahasanya, motivasinya, sikapnya, dan hukumannya yang akrab. Pelaksanaan pembelajaran

dilaksanakan di ruang karawitan, meskipun ruangan sudah konsisten tetapi instrumen gamelan tidak bisa bergerak dan berpindahpindah tempat. Peserta didik rajin mengulangi materi yang sudah pernah diberikan oleh guru. Langkah pelaksananaan pembelajaran dibagi menjadi tiga langkah, yaitu kegiatan awal, inti dan penutup. Kegiatan awal guru memberi salam dan berdoa bersama. Setelah itu, guru melakukan presensi kepada peserta didik dan memberi motivasi. Setelah melakukan kegiatan tersebut guru menyiapkan sarana pembelajaran seperti penghapus, spidol, LCD Proyektor, dan

Soundsystem. Sedangkan pada kegiatan inti, guru mengawali dengan mendengarkan rekaman gending Lesung Jumengglung yang akan diproses, kemudian diajarkan materi pola irama gending dasarterlebih dahulu. Menjelaskan materi yang diberikan secara perlahan sehingga peserta didik mengerti dan memahami, setelah itumateri dilanjutkan dengan membacaan notasi pada gending Lesung Jumengglung. Bagian akhir pembelajaran, guru menutup kegiatan pembelajaran dengan menyimpulkan, mengulang materi gending Lesung Jumengglungdari intro sampai coda, dan menutup pembelajaran dengan berdoa bersama.

Evaluasi pembelajaran terdiri dari dua penilaian yaitu penilaian proses dan penilaian hasil. Penilaian proses untuk memberikan kesempatan kepada peserta didik terlebih dahulu untuk mengoreksi diri dan menilai kekurangan yang peserta didik lakukan selama pembelajaran karawitan berlangsung, 
kemudian guru mengevaluasi semua aktifitas yang terjadi saat proses

pembelajaran karawitan. Guru melalukan pemilihan terhadap peserta didik yang mampu dan rajin mengikuti latihan untuk mengikuti perlombaan. Sedangkan peserta didik yang kurang mampu dan tidak rajin ikut latihan guru menawarkan untuk pentas di sekolahan. Guru juga menawarkan kepada peserta didik nilai A sebagai penunjang nilai rapor, dengan catatan peserta didik telah melaksanakan sesuai dengan materi dalam proses pembelajaran karawitan. Sedangkan peniliaian hasil peserta didik dalam proses latihan ekstrakurikuler karawitan di SMAN 1 Karangan adalah hasil prestasi mengikuti perlombaan tingkat kabupaten maupun tingkat provisi Jawa Timur. Hasil kerja keras peserta didik selama mengikuti proses

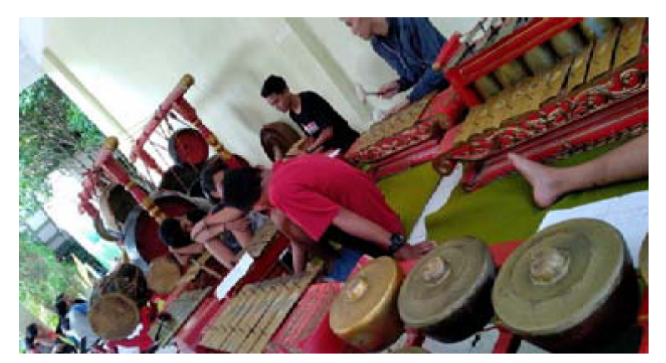

Gambar 1. Latihan persiapan lomba

latihan berupa kejuaraan menjadi motivasi tujuan proses latihan. Tujuan proses latihan karawitan untuk melatih keterampilan peserta didik dan mengembangkan bakat dan minat dengan meraih prestasi.

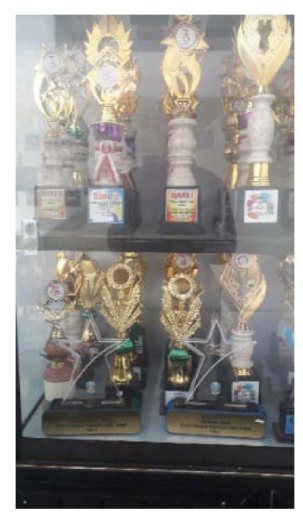

Gambar 2. Prestasi ekstrakurikuler karawitan

\section{KESIMPULAN}

Berdasarkan hasil penelitian tentang "Proses Pembelajaran Karawitan pada kegiatan Ekstrakurikuler di SMAN 1 Karangan Kabupaten Trenggalek “, diperoleh kesimpulan yaitu guru ekstrakurikuler karawitan telah melaksanakan rangkaian proses yang lengkap dari perencanaan, pelaksanaan, dan evaluasi. Ketiga rangkaian ini memberikan motivasi berkelanjutan dan bukti nyata hasil belajar pada pementasan di perlombaan maupun non perlombaan.

Berdasarkan penelitian yang telah dilakukan, saran yang diberikan

peneliti adalah saran untuk mahasiswa dan saran untuk sekolah. Saran untuk mahasiswa, bahwa penelitian ini diharapkan agar mampu melanjutkan penelitian tentang pembelajaran karawitan pada kegiatan ekstrakurikuler yang dapat menghasilkan penelitian baru disekolah lain yang ada di Kabupaten Trenggalek untuk mengetahui jenis atau teknik serta strategi mengenai kegiatan ekstrakurikuler karawitan. Saran untuk pihak sekolah, bahwa penelitian ini diharapkan dapat menumbuhkan kesadaran pihak sekolah SMAN 1 Karangan Trenggalek untuk menyediakan kebutuhan soundsystem dan pembenahan gamelan yang larasnya sudah berubah sehingga kegiatan ekstrakurikuler karawitan di SMAN 1 Karangan dapat berjalan lebih optimal dan nantinya dapat memberikan prestasi yang dalam bidang seni bagi sekolah khususnya di bidang seni tradisi.

\section{DAFTAR PUSTAKA}

Abadi, Damai. 2016. Pembelajaran Seni Karawitan Jawa Pada Mata Pelajaran Seni Budaya Di SMA Katolik Diponegoro Kota Blitar. Skripsi tidak diterbitkan. Malang : FS UM.

Azis, Abdul. 2012. Metode dan Model-Model Mengajar. Bandung : Alfabeta.

Cepi Riyana, Susilana Rudi.2009. Media Pembelajaran. Bandung : CV. Wacana Prima.

Daryanto. 2005. Evaluasi Pendidikan. Jakarta: Rineka Cipta. 
Gasita, Octavian.2016. Strategi Pembelajaran Karawitan Pada Kelas Seni Di SMP Negeri 4 Malang. Skripsi tidak diterbitkan. Malang : FS UM.

Jamalus, 1988. Musik dan Praktek Perkembangan Buku Sekolah Pendidikan Guru. Jakarta : CV. Titik Terang.

Jazuli. 2008. Paradigma Kontekstual Pendidikan Seni. Semarang : Uness University Press.

Majid, Abdul. 2013. Perencanaan Mengembangkan Standar Kompetensi Guru. Bandung : PT. Remaja Rosdakarya.

Marinda, Fahmi. 2017. Pembelajaran Ekstrakurikuler Karawitan Di Sekolah Dasar Inklusi Negeri 1 Trirenggo Bantul Yogyakarta. Skripsi (online), UNY YOGYAKARTA http://eprints.uny. ac.id/52864/1/FAHMI\%20MARINDA. pdf diunduh pada tanggal 03 April 2018 pukul 13.15 WIB.

Moleong, Lexy J. 2014. Metode Penelitian Kualitatif. Bandung : PT. Remaja Rosdakarya.

Nunuk, Suryani. 2012. Strategi Belajar Mengajar. Yogyakarta : Ombak.

Palgunadi, Bram. 2002. Serat Kandha Karawitan Jawi. Bandung : ITB.

Permendikbud No. 62. 2014. Kegiatan Ekstrakurikuler Pada Pendidikan Dasar dan Pendidikan Menengah. Jakarta : Permendikbud.

Purwadi. 2006. Seni Karawitan Jawa: Ungkapan keindahan dalam musik gamelan. Bandung : Hanan Pustaka.

Sanjaya, Wina.2013. Strategi Pembelajaran Berorientasi Standar Proses Pendidikan. Jakarta : Kencana Prenadamedia Group.

Sarwinto, Alfris. 2016. Strategi Pembelajaran Ekstrakurikuler Karawitan Di SMPN 1 Bantul. Skripsi (online), UNY YOGYAKARTA http:// eprints.uny.ac.id/40728/1/Skrips AlfrisSarwinto 11208244016.pdf di unduh pada tanggal 16 Februari 2018 pukul 20.15 WIB.
Sofan, Amri. 2010. Proses Pembelajaran Kreatif dan Inovatif dalam kelas. Jakarta: PT. Prestasi Putrakaraya.

Sudjana, Nana.2013. Dasar-Dasar Proses Belajar Mengajar. Bandung : Sinar Baru Algesindo.

Toto Ruhimat. 2011. Kurikulum dan Pembelajaran. Jakarta : PT Raja Grafindo Nusa

Universitas Negeri Malang. 2010. Pedoman Penulisan Karya Ilmiah: Skripsi, Tesis, Disertasi, Artikel, Makalah, Laporan Penelitian. Edisi kelima, Malang: Biro Administrasi, Perencanaan Dan Sistem Informasi Bekerjasama Dengan Penerbit Universitas Negeri Malang.

Khusairi, Abdul Rozaq Fathin, Rully Aprilia Zandra, and Ninik Harini. 2019. "Ketrampilan Memainkan Recorder Melalui Model Kooperatif Tipe Jigsaw." Promusika 7(1):1-10.

Rahmawati, Arin Pradikasetya, Endang Wara Suprihatin Dyah Pratamawati, and Rully Aprilia Zandra. 2017. "M-Learning Teori Musik Dalam Aplikasi Smartphone Android." Journal of Art, Design, Art Education And Culture Studies (JADECS) 2(2):128-35.

Zandra, Rully Aprilia. 2014. "Sejarah Musik Keroncong Di Surabaya." Imaji 12(1):7484.

Zandra, Rully Aprilia. 2019. "Keroncong Gaya Keempat (Kajian Bentuk Dan Gaya Penyajian)." Journal of Art, Design, Art Education And Culture Studies (JADECS) 4(1):39-47. 